\title{
Medicine \& Humanities At University Of Ottawa's Faculty Of Medicine: Developing A Curriculum For Our Undergraduate Medical Education Program
}

\author{
Dr. Pippa Hall, $\mathrm{MD}^{1}$ \\ ${ }^{1}$ Faculty of Medicine, University of Ottawa
}

The Medicine \& Humanities Program in the undergraduate medical education (UGME) curriculum in the Faculty of Medicine at the University of Ottawa is a new and evolving program. It seeks to enhance our students' education by formally infusing both our French and English streams' curricula with concepts of health, medicine and healing through the humanities, including medical history, philosophy, the arts and literature. There is increasing awareness of the importance of the humanities in the education of health professionals. Often referred to as the 'art of medicine', the humanities contribute to a range of skills necessary for patient interaction, from communication, through cultural sensitivity, to the human values that underpin ethics and professionalism in medicine. In their turn, these values and skills are founded on our cultural traditions, evolving throughout history of medicine. Our current vision of ethics, law, philosophy, human diversity and respect for all patients is a result of this evolution and will change yet again. Medical students need to recognize this, often ephemeral, aspect of medicine.
Our program consists of mandatory curricular components for all students, and extracurricular or elective components for students who wish to pursue medicine, the arts and humanities in more depth. In 2014, a process was developed for students with special interests in this area to obtain either a special recognition for their interest in, and commitment to, the humanities and medicine, or a certificate of excellence in Humanities in Medicine, for which a special pre-approved project is required. All medical students are eligible. Students must submit a request, and document the number of hours they spend on the humanities-based activity. The request is reviewed and adjusted if necessary, and on completion of the activity, members of the Medicine \& Humanities committee (or their delegates) award the final number of credits. Figure 1 is a diagrammatic representation of the curricular organization.

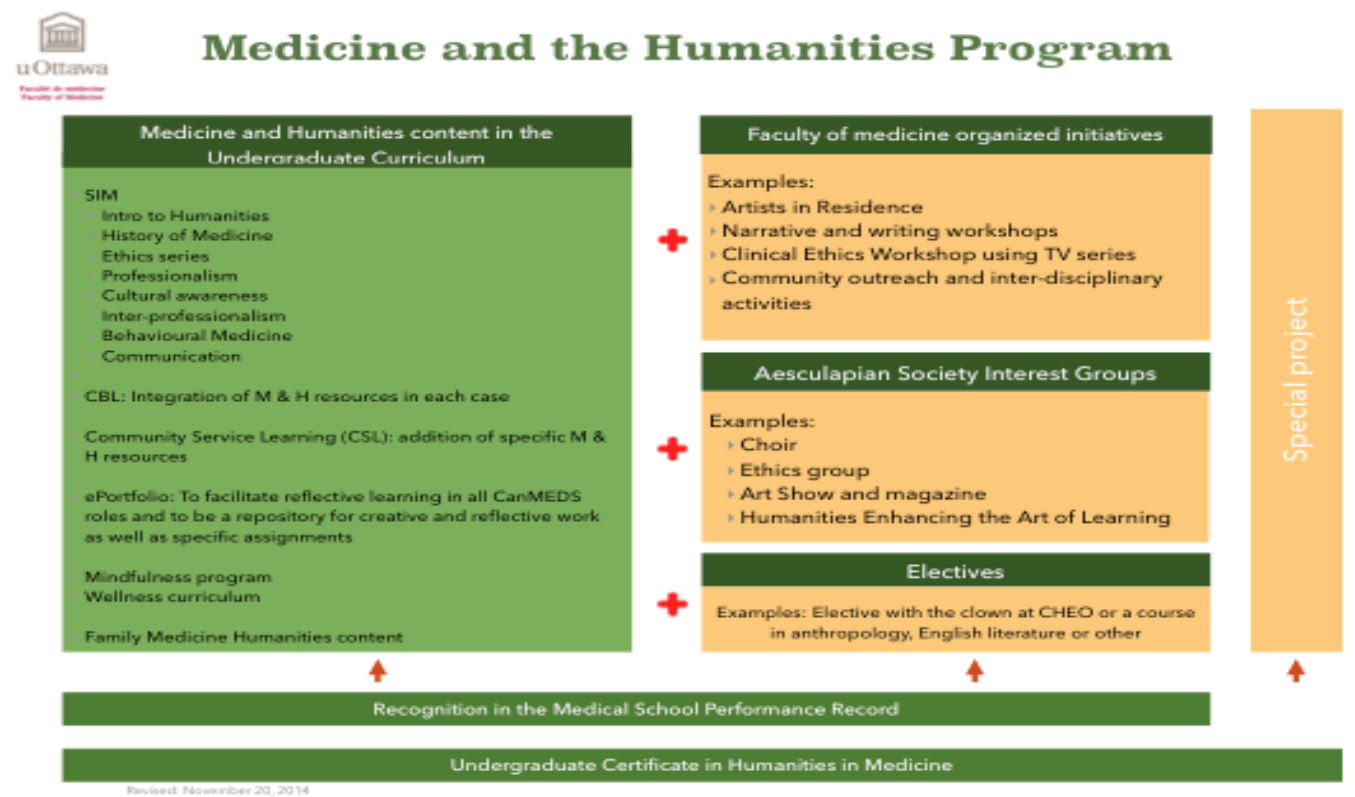

Figure 1

Keywords: Person; Wellness; Humanities; Medical Education 